\title{
From the Editor
}

\author{
Therese Jones
}

Published online: 7 September 2013

(C) Springer Science+Business Media New York 2013

As we end our 2013 publication cycle, we are delighted to honor the winners of the annual William Carlos Williams Medical Student Poetry Competition and to share their verse in this special theme issue of the journal. They are:

- Allie Gips who is now a third-year medical student at the Icahn School of Medicine at Mount Sinai. Allie writes that this poem came to her "essentially fully drafted on a Saturday in November... borne from one of those rare and beautiful mornings when you are at complete peace with the moment of space and time that you are occupying...so much at peace that you yearn to bottle up a bit of the calm for the storms that are always sure to come." Her poem, "prayer song," placed first in this year's competition.

- Amanda Rutishauser who is now a second-year medical student at the Michigan State University College of Human Medicine in Grand Rapids. Amanda wrote this poem as an opportunity to explore the question of where our energy goes when we die. Having learned in a physics course, that "energy is neither created nor destroyed," she poses that fundamental question, noting that "I didn't intend to answer it...just ask it in a way that seemed personal. My greatest hope for the poem is that it will inspire discussion and reflection." Her poem, "Neither Created Nor Destroyed," placed second.

- Michelle C. Liu who is now a fourth-year student at the Icahn School of Medicine at Mount Sinai. Michelle wrote this poem during her first clinical rotation as a third-year student on obstetrics and gynecology after "witnessing" a hysterectomy: "The experience felt strangely surreal and bizarre (even comical), as if I couldn't quite believe I was standing in the operating room, scrubbed in, a complete stranger to this woman who trusted us to remove her uterus." Her aptly titled poem, "a hysterectomy," placed third.

On behalf of the editorial board of $J M H$, I congratulate these poets and future physicians, and we look forward to publishing and reading their work in future issues.

T. Jones $(\bowtie)$

Anschutz Medical Campus, University of Colorado, 13001 E. 17th Pl., Aurora, CO 80045, USA

e-mail: Therese.Jones@ucdenver.edu 